\title{
Characterization of the tumor marker mucl 6 (ca I 25) expressed by murine ovarian tumor cell lines and identification of a panel of cross-reactive monoclonal antibodies
}

\author{
Cara AR Goodell ${ }^{1}$, Jennifer A Belisle ${ }^{1}$, Jennifer AA Gubbels'1, \\ Martine Migneault ${ }^{2}$, Claudine Rancourt ${ }^{2}$, Joseph Connor ${ }^{1}$, \\ Muthusamy Kunnimalaiyaan ${ }^{3}$, Rachel Kravitz ${ }^{4}$, Ward Tucker ${ }^{4}$, \\ Michael Zwick ${ }^{5}$ and Manish S Patankar*1
}

\begin{abstract}
Address: ${ }^{1}$ Department of Obstetrics and Gynecology, University of Wisconsin-Madison, Madison, Wisconsin-53792, USA, ${ }^{2}$ Department of Microbiology and Infectiology, Universite de Sherbrooke, Sherbrooke, Canada, ${ }^{3}$ Department of Surgery, University of Wisconsin-Madison, Wisconsin-53792, USA, ${ }^{4}$ NeoClone Biotechnology, Madison, Wisconsin-53713, USA and ${ }^{5}$ AndroBioSys Inc, 73 High Street, Buffalo, New York 14203-1149, USA

Email: Cara AR Goodell - caraamy@gmail.com; Jennifer A Belisle - jbelisle@wisc.edu; Jennifer AA Gubbels - arens@wisc.edu; Martine Migneault - martinemig@hotmail.com; Claudine Rancourt - Claudine.Rancourt@USherbrooke.ca;

Joseph Connor - jpconnor@wisc.edu; Muthusamy Kunnimalaiyaan - kunni@surgery.wisc.edu; Rachel Kravitz - rkravitz@neoclone.com; Ward Tucker - wtucker@biosentinelpharma.com; Michael Zwick - mzwick@androbiosys.com; Manish S Patankar* - patankar@wisc.edu

* Corresponding author
\end{abstract}

Published: 18 June 2009

Journal of Ovarian Research 2009, 2:8 doi:10.1186/1757-2215-2-8

This article is available from: http://www.ovarianresearch.com/content/2/I/8

(c) 2009 Goodell et al; licensee BioMed Central Ltd.

This is an Open Access article distributed under the terms of the Creative Commons Attribution License (http://creativecommons.org/licenses/by/2.0), which permits unrestricted use, distribution, and reproduction in any medium, provided the original work is properly cited.
Received: 5 February 2009

Accepted: 18 June 2009

which permits unrestricted use, distribution, and reproduction in any medium, provided the original work is properly cited.

\begin{abstract}
Objectives: The ovarian tumor marker CAI25 is expressed on human MUCI6, a cell surface bound mucin that is also shed by proteolytic cleavage. Human MUCI6 is overexpressed by ovarian cancer cells. MUCI6 facilitates the binding of ovarian tumor cells to mesothelial cells lining the peritoneal cavity. Additionally, MUCI6 also is a potent inhibitor of natural killer cell mediated anti-tumor cytotoxic responses. Extensive studies using human as well as murine ovarian tumor cell models are required to clearly define the function of MUCI6 in the progression of ovarian tumors. The major objective of this study was to determine if the murine ovarian tumor cells, MOVCAR, express Mucl 6 and to characterize antibodies that recognize this mucin.
\end{abstract}

Methods: RT-PCR analysis was used for detecting the Mucl 6 message and size exclusion column chromatography for isolating Mucl 6 produced by MOVCAR cells. Soluble and cell-associated murine Muc 16 were analyzed, respectively, by Western blotting and flow cytometry assays using a new panel of antibodies. The presence of $\mathrm{N}$-linked oligosaccharides on murine Mucl 6 was determined by ConA chromatography.

Results: We demonstrate that murine Mucl 6 is expressed by mouse ovarian cancer cells as an $\sim 250 \mathrm{kDa}$ glycoprotein that carries both $\mathrm{O}$-linked and $\mathrm{N}$-linked oligosaccharides. In contrast to human $\mathrm{MUCl6}$, the murine ortholog is primarily released from the cells and cannot be detected on the cell surface. Since the released murine Mucl 6 is not detected by conventional antiCAI 25 assays, we have for the first time identified a panel of anti-human MUCI 6 antibodies that also recognizes the murine counterpart.

Conclusion: The antibodies identified in this study can be used in future purification of murine Mucl 6 and exhaustive study of its properties. Furthermore, the initial identification and characterization of murine Mucl6 is a vital preliminary step in the development of effective murine models of human ovarian cancer. These models will aid in the further elucidation of the role that human MUCI 6 plays in the etiology and progression of ovarian tumors. 


\section{Background}

Epithelial ovarian cancer (EOC) is the fifth leading cause of all female cancer-related deaths in the western world [1]. Despite its prevalence, this disease is marked by difficulties in early diagnosis as well as lack of an effective screening test. The major marker of human EOC is the CA125 peptide epitope, serum levels of which are elevated in EOC patients [2]. The CA125 epitope is contained in MUC16, a 2-5 million Da transmembrane mucin that is over expressed in EOC $[3,4]$. As a shed type of mucin, MUC16 is both expressed on the cell surface and released following proteolytic cleavage into the extracellular space [5].

Recent studies indicate that MUC16 is not only important as a tumor marker but also promotes peritoneal metastasis of ovarian cancer and suppresses the cytolytic responses of human natural killer cells $[6,7]$. The physiological function of this mucin is not known; however, its biochemical properties have constrained studies on this molecule. The high molecular weight of MUC16 requires the use of extensive molecular biological approaches to study the importance of this mucin in the pathogenesis of ovarian cancer. In addition, a thorough study of MUC16 expressed in mouse models for ovarian cancer will also aid in understanding its physiological roles.

Recently, several murine ovarian tumor models have been developed [8-10]. In one particular model, transgenic mice were generated expressing the SV40 T-antigen under the direct influence of the Mullerian inhibitory substance (an ovary-specific gene), and the mice spontaneously developed ovarian cancers resembling poorly differentiated ovarian adenocarcinomas in women $[8,11]$. Murine ovarian tumor cell lines, designated as MOVCAR, have been generated from these tumors [8]. These cell lines provided us an opportunity to perform biochemical and physiological studies on the murine counterpart of MUC16, designated as Muc16. Here we report the expression and initial biochemical characterization of Muc16 expressed by the MOVCAR cells. Specifically, we identify expression of Muc16 mRNA and provide evidence that, unlike MUC16, the murine ortholog is not expressed on the cell surface but is instead primarily released from the MOVCAR cells. In addition, we have for the first time identified specific monoclonal antibodies that can be used in future studies of murine Muc16.

\section{Methods}

\section{Cells, antibodies, and other reagents}

The anti-MUC16 antibody VK8 [12] was a kind gift from Beatrice Yin (Memorial Sloan Kettering, New York, USA). The panel of anti-MUC16 mouse monoclonal antibodies was generated against human ascites derived MUC16 using the ABL-MYC transformation technology $[13,14]$.
The four murine ovarian cancer cell lines-MOVCAR 1, 2, 9 , and 10-were kindly provided by Dr. Denise Connolly (Fox Chase Cancer Center, Philadelphia) and cultured in DMEM supplemented with $10 \%$ FBS, $0.2 \%$ ITS and $1 \%$ antibiotic-antimycotic. The human epithelial ovarian tumor cell lines OVCAR-3, SKOV-3, and CAOV-3 were purchased from ATCC.

\section{RT-PCR}

Total RNA was isolated from MOVCAR cell lines using the Qiagen RNeasy ${ }^{\oplus}$ Mini kit and $2 \mu \mathrm{g}$ of total RNA was reverse transcribed. PCR reactions were performed with $2.5 \mu \mathrm{L}$ of cDNA. For each sample, a control tube containing all reagents except template cDNA was prepared. cDNA was amplified with the following primer pairs from Integrated DNA Technologies: Muc16 5'-TGCCACCTACCAGTTGAAAG-3' and 5'-GTACCGCCAAGCAGATGAG-3'; GAPDH 5'-TGCTGAGTATGTCGTGGAGTCTA-3' and 5'AGTGGGAGTTGCTGTTGAAGTCG-3'. The amplified Muc1 6 cDNA from MOVCAR-2 cells was sequenced at the University of Wisconsin-Madison Biotechnology Center.

\section{Flow cytometry}

Cells $\left(2.5 \times 10^{5}\right)$ were fixed with $2 \%$ paraformaldehyde, washed three times with sterile filtered PBS/1\% BSA (PBSBSA), and permeabilized with $0.1 \%$ Triton X-100 on ice. Unfixed cells $\left(2.5 \times 10^{5}\right)$ were kept on ice during this time. All cells were incubated with primary and secondary antibodies for 30 minutes on ice. The $618 \mathrm{~F}$ and $653 \mathrm{~F}$ antibodies were used at 1:250 dilutions in PBS-BSA. VK8 from cell culture supernatant was used directly for labeling. The FITC-conjugated goat anti-mouse (GAM) IgG, Fc specific secondary antibody (Jackson ImmunoResearch) was used for detection at 1:100.

\section{Protein isolation, electrophoresis, and Western blotting}

Soluble Muc16 was isolated from MOVCAR-2 serum-free spent media which was concentrated 20 -fold. Approximately $5 \mathrm{~mL}$ of concentrated media was loaded onto a Sepharose-CL4B (Sigma) column $(1.5 \mathrm{~cm} \times 42 \mathrm{~cm})$ preequilibrated with $10 \mathrm{mM}$ ammonium bicarbonate buffer and $1 \mathrm{~mL}$ collected fractions were monitored for absorbance at $280 \mathrm{~nm}$. The desired fractions were pooled and lyophilized. Soluble human MUC16 was isolated as described in our previous study [15]. Cell lysates were prepared by treating the ovarian tumor cells with Tris buffered saline containing $0.5 \%$ Triton X-100 and a cocktail of protease inhibitors (Sigma).

For Western blotting, $25 \mu \mathrm{g}$ of protein was separated on 7.5\% SDS-PAGE gels and electroblotted on a PVDF membrane. The membranes were sequentially overlaid with anti-human MUC16 antibodies followed by horseradish peroxidase labeled GAM IgG (Pierce; 1:20,000 dilution). Signals were detected by using the West Pico kit (Pierce). 
Coomassie Blue and silver staining of gels was performed using protocols established in our laboratory.

\section{ConA Chromatography}

Concentrated harvest media from MOVCAR-2 cells containing $22 \mathrm{mg}$ of total protein was loaded onto a $5 \mathrm{~mL}$ Concanavalin A (ConA) column (Sigma; ConA immobilized on $4 \%$ cross-linked agarose) equilibrated in $1 \times$ ConA buffer (100 mM Tris $\mathrm{HCl}$ containing 1.5 M sodium chloride, $10 \mathrm{mM}$ calcium chloride, $10 \mathrm{mM}$ magnesium chloride, and $0.2 \%$ sodium azide). The column was eluted with ConA buffer and fractions were monitored for absorbance at $280 \mathrm{~nm}$. The bound glycoproteins were eluted by washing with a step gradient $(100,250$, and 500 $\mathrm{mM}$ ) of $\alpha$-methylmannopyranoside ( $\alpha$-Me-Man). Fractions from eluted peaks were pooled, and the proteins were analyzed by Western blotting.

\section{Results}

\section{Expression of Muc 16 mRNA in MOVCAR cells}

We first conducted RT-PCR experiments to determine expression of Muc16 by the MOVCAR cells. Specific primers for Muc16 were designed around the unique domain which was identified based on its percent identity with the corresponding region of MUC16. The region between 25605 bp to 26125 bp of the Muc16 sequence reported in GenBank accession no. XM 911929.2 was amplified by these primers. Muc16 mRNA was expressed in each of the four MOVCAR cell lines tested by RT-PCR (Fig. 1). After DNA sequencing, the PCR product from the MOVCAR-2 cell line was found to have 99\% identity with the projected sequence of Muc16. Although Muc16 was always expressed in these cells, the level of Muc16 mRNA varied in different passages (data not shown).

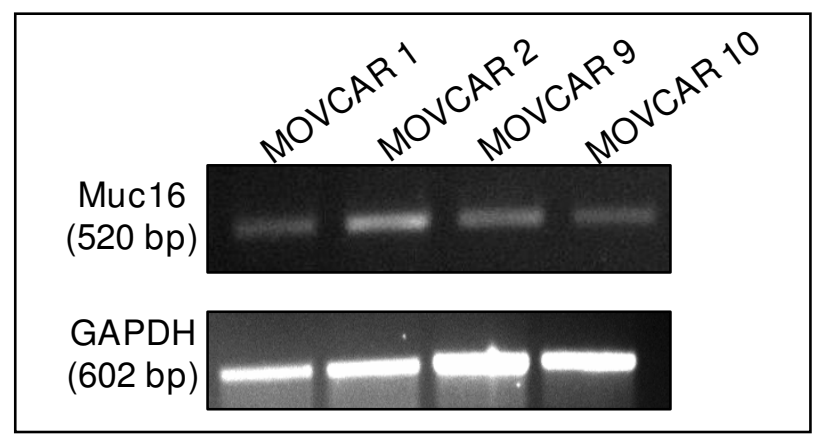

Figure I

RT-PCR verification of Mucl 6 mRNA expression in four MOVCAR cell lines. GAPDH gene was used as a housekeeping control.

\section{Detection of Soluble Muc 16 in MOVCAR media}

Soluble MUC16 is shed into the spent harvest media of the human epithelial ovarian tumor cell line, OVCAR-3. The shed MUC16 can be isolated from the media following concentration and separation by size exclusion chromatography [15]. We therefore determined if Muc16 was present in the spent media from MOVCAR-2 cells.

We consistently found that the MOVCAR-2 media purification profiles on a Sepharose CL-4B size exclusion column followed the same pattern as the OVCAR-3 media profiles (Fig. 2) [15]. The murine Muc16 was only slightly retarded on this column (Fig. 2) and was initially identified (data not shown) by Alcian Blue staining [16].

To specifically identify Muc16, we conducted Western blot analysis of Pool 1 using MUC16 specific VK8 and OC125 antibodies. No bands for Muc16 were detected in these analyses. The widely employed clinical serum CA125 assay was also unable to detect CA125 in spent media of MOVCAR-2 cells. We therefore tested a panel of ten anti-MUC16 antibodies that we recently generated using the novel ABL-MYC technology. All of these antibodies were able to detect an approximately $250 \mathrm{kDa}$ band for Muc16 (Fig. 3). The binding to Muc16 was weaker as compared to MUC16 and was usually observed at 1:250 dilution of the primary antibodies.

\section{I8F and 653F specifically recognize human MUCI 6}

Two antibodies from the panel that efficiently recognized Muc1 6 by Western blotting were $618 \mathrm{~F}$ and 653F. When a purified preparation of human MUC16 was analyzed by Western blotting, the $618 \mathrm{~F}$ antibody exhibited a similar

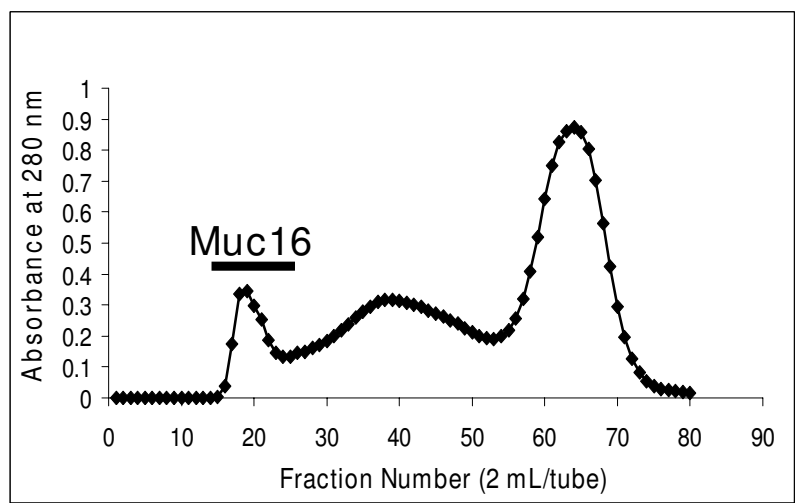

\section{Figure 2}

Purification of Soluble Mucl 6 on a Sepharose CL-4B Column. Concentrated MOVCAR-2 spent media was separated as described in Methods. Fractions located under the bar stained positive for mucin with Alcian Blue and Western blotting. 


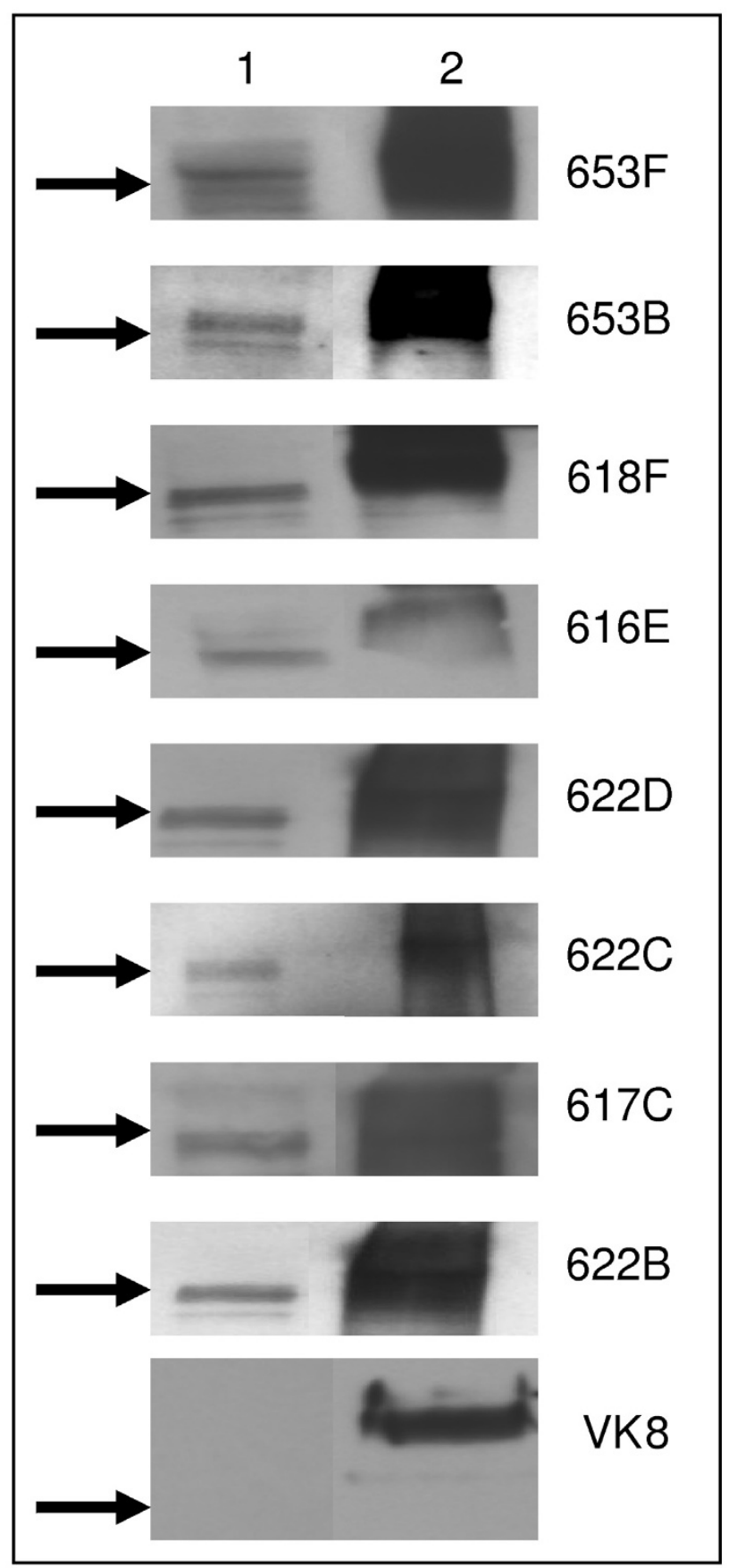

\section{Figure 3}

Identification of soluble Muc 16 and MUCI 6 by Western blotting. Purified MUCI6 (25 $\mu$ g total protein/lane) from MOVCAR-2 (lane I) and OVCAR-3 cells (lane 2) was electrophoresed by SDS-PAGE and probed with a panel of anti-MUCI 6 monoclonal antibodies. Arrows indicate migration of $250 \mathrm{kDa}$ molecular weight marker and identity of antibody used is shown on the right of each blot. banding pattern to that shown by the VK-8 antibody (Fig. $4 \mathrm{~A})$. Using flow cytometry we also demonstrated that both $618 \mathrm{~F}$ and $653 \mathrm{~F}$ specifically bind to the OVCAR-3 but not to the MUC16 neg SKOV-3 or CAOV-3 cells (Fig. 4B). The binding of $618 \mathrm{~F}, 653 \mathrm{~F}$ and VK-8 to the OVCAR-3, SKOV-3, and CAOV-3 cells was comparable. Considering the demonstrable specificity of $618 \mathrm{~F}$ and $653 \mathrm{~F}$ for MUC16 and their ability to recognize Muc16 from the MOVCAR2 spent media, we primarily conducted all of our further experiments with these two antibodies.

\section{Binding of murine muc 16 to the Lectin ConA}

Although mucins are known to express high amounts of O-glycans, MUC16 also carries a significant proportion of $\mathrm{N}$-linked oligosaccharides. To determine if Muc16 also expresses $\mathrm{N}$-linked glycans, we loaded the concentrated spent media from MOVCAR-2 cells on a ConA column. The flow-through fractions from the column were collected and the retained material was eluted using sequential washes containing increasing concentrations of $\alpha-\mathrm{Me}$ Man (Fig. 5a). Muc16 was detected in all of the $\alpha$-Me-Man fractions but not in the flow-through pool by Western blot analysis using the 653F antibody (Fig. 5b).

\section{Murine mucl 6 is not expressed on the MOVCAR cell surface}

Having identified soluble forms of Muc16 by Western blotting, we investigated whether this mucin was also expressed on the cell surface of MOVCAR cells. We consistently found little to no extracellular Muc16 expression on the MOVCAR-10 cells when the expression of this mucin was determined by flow cytometry using the $618 \mathrm{~F}$ antibody (Fig. 6a). On the other hand, high levels of intracellular Muc16 were detected in the MOVCAR-10 cells using the $618 \mathrm{~F}$ antibody (Fig. 6b). These results are in sharp contrast with the intense extracellular binding of this antibody found on OVCAR-3 cells (Fig. 4b).

Correcting for background fluorescence of the isotype control, our results for all MOVCAR cell lines showed a clear expression of intracellular Muc16 and only minimal presence of Muc16 on the cell surface (Figs. 6a-d). Similar results were obtained with both the $618 \mathrm{~F}$ and $653 \mathrm{~F}$ antibodies (Fig. 6c and 6d).

\section{Discussion}

We have identified soluble and cell-associated Muc16 in MOVCAR cells. While soluble MUC16 is over 3 million $\mathrm{Da}$, Western blots indicate that the murine counterpart is significantly smaller, at approximately $250 \mathrm{kDa}$. With its tertiary structure intact during size exclusion chromatography, however, Muc16 behaves as a much larger protein. This suggests intermolecular crosslinking in Muc16 similar to that observed in other mucins. Extensive glycosylation of Muc16 arising from the presence of O-linked and 

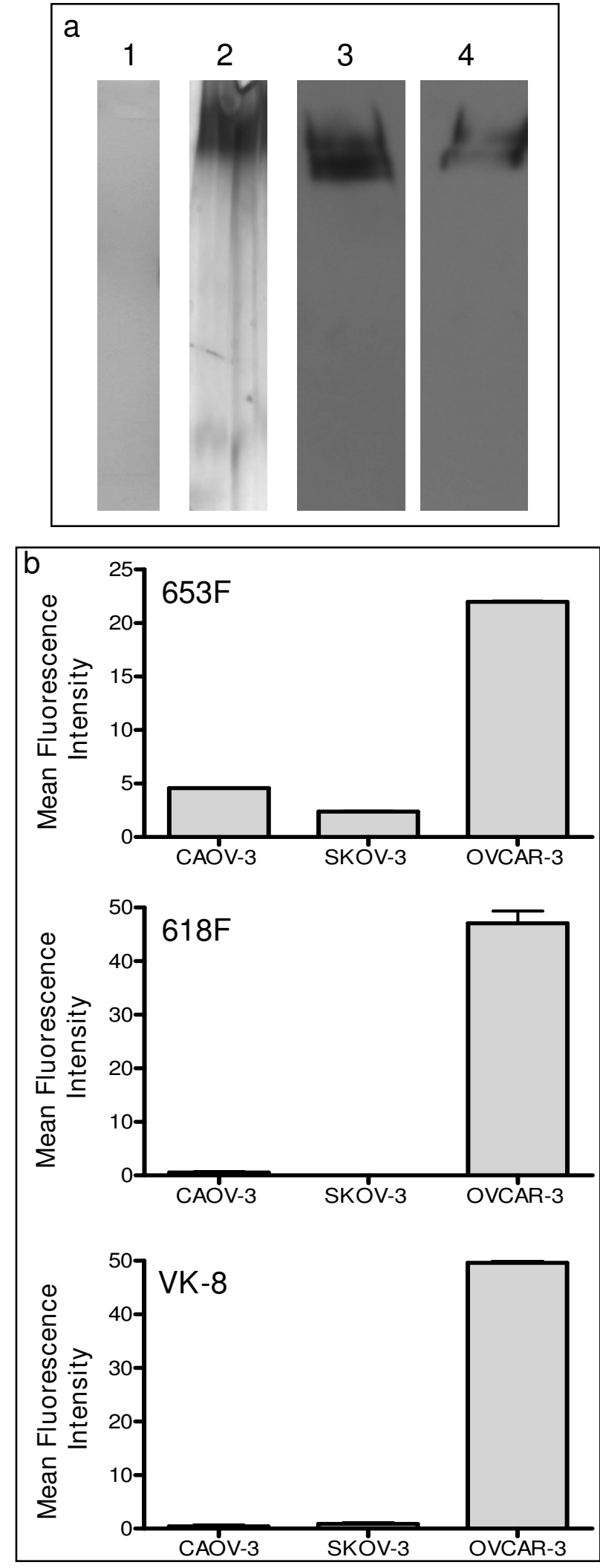

Figure 4

\section{Figure 4}

Specificity of 6 I 8F for human MUC I6. (A) Purity of human MUCI 6 isolated from spent media of OVCAR-3 cells as determined by Coomassie Blue (I) and silver staining (2) of SDS-PAGE gel. Western blot analysis of the purified human MUCI 6 was conducted using the $618 \mathrm{~F} \mathrm{(3)} \mathrm{and} \mathrm{the}$ VK-8 (4) antibodies. (B) MUCI 6 expression on OVCAR-3, CAOV-3, and SKOV-3 was determined by flow cytometry using $653 \mathrm{~F}, 6 \mathrm{I} 8 \mathrm{~F}$, or VK-8 as the primary antibodies. Mean fluorescence intensity of the corresponding isotype controls was subtracted in each case. Data shown is mean of two independent experiments. Note that the binding of $618 \mathrm{~F}$, $653 \mathrm{~F}$ and VK-8 to these three cell lines is comparable.
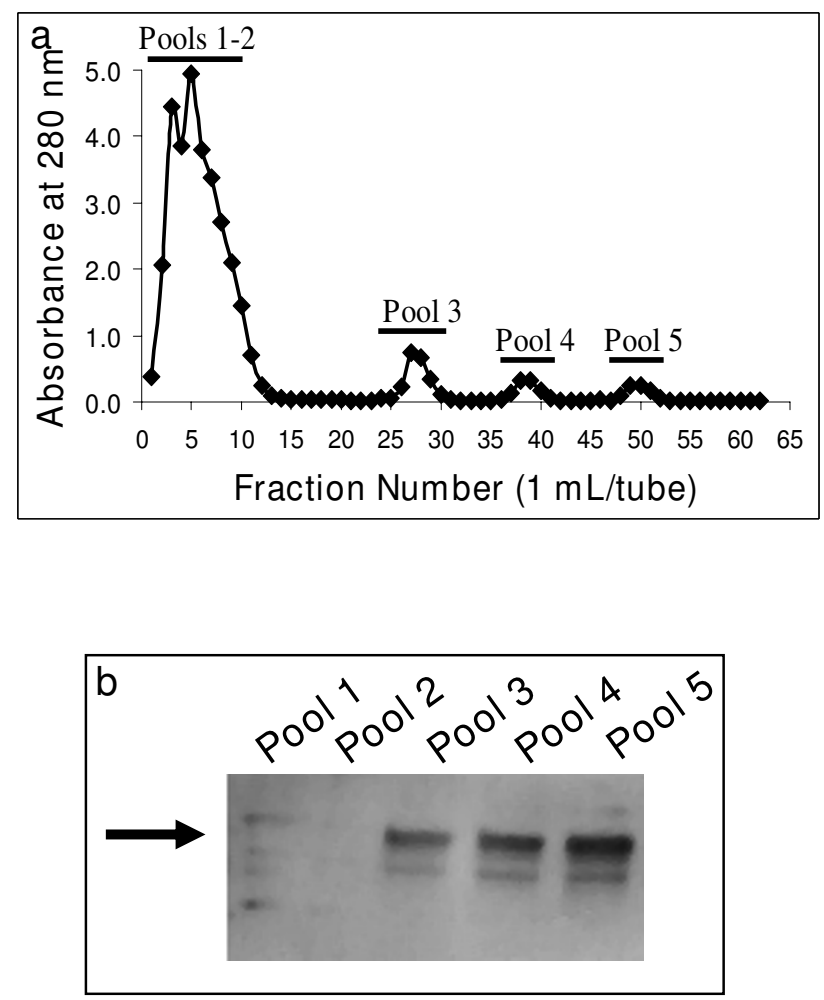

Figure 5

Binding of murine Muc 16 to the lectin ConA. (A) Concentrated MOVCAR-2 spent media was separated on a ConA affinity column. Fractions eluted with ConA buffer were combined in pools I and 2. Fractions eluted with 100 , 250 , and $500 \mathrm{mM} \alpha-M e-M a n$ concentrations were combined in pools 3-5, respectively. (B) Pooled fractions were electrophoresed by SDS-PAGE and probed with 653F. The arrow indicates migration of $250 \mathrm{kDa}$ molecular weight marker. Murine Mucl 6 was detected primarily in pools 3-5. 

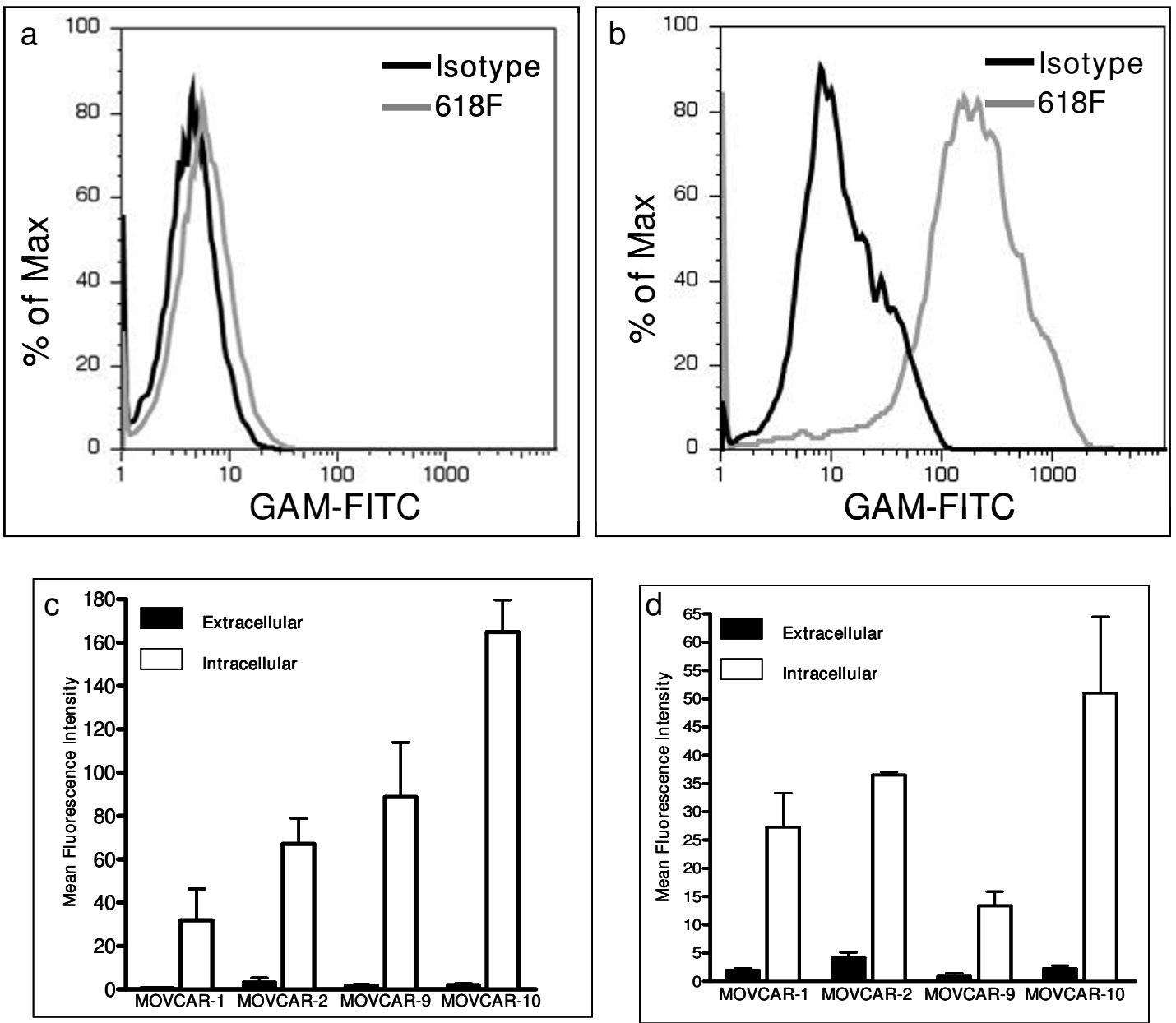

\section{Figure 6}

Extra-and intracellular Muc 16 expression by MOVCAR cells. (A) MOVCAR- 10 cells were labeled with 6 I8F (grey line) and analyzed for cell surface expression of Mucl 6 by flow cytometry. Isotype control is shown by dark line. (B) MOVCAR-I0 cells were fixed and expression of intracellular Muc 16 was detected by using the 6I8F antibody (grey line). Dark line shows isotype control. (C) Expression of cell surface and intracellular Mucl 6 in the four MOVCAR cell lines was determined by flow cytometry using the $618 \mathrm{~F}$ antibody. The mean fluorescence intensity for the binding of $618 \mathrm{~F}$ to the cell surface and intracellular Mucl 6 is plotted after subtracting the mean fluorescence intensity for the matched isotype controls. Each measurement is a mean of two independent experiments. (D) Same as in (C) except 653F was used for detection of murine Mucl6.

N-linked oligosaccharides, as demonstrated in our studies, may also contribute to its large tertiary structure.

Given the lack of cell surface Muc16 on MOVCAR cells, we can make important distinctions between the human and murine forms of the mucin. MUC16 is both expressed on the cell surface and shed from the cell in soluble forms. Muc16, on the other hand, is detected primarily in the spent media and in the intracellular environment. This observation indicates that the Muc16 is either rapidly cleaved from the cell surface by a very active proteolytic enzyme or is an alternatively spliced form that is primarily secreted by the MOVCAR cells. Our future studies will focus on deciphering the mechanisms that lead to the generation of the shed Muc16.

The shed and cell surface bound MUC16 play important roles in the progression of human ovarian tumors. While the shed MUC16 appears to have major influence on the cytolytic function of natural killer cells, the cell surface bound MUC16 is important for binding of the ovarian tumor cells to the mesothelial cells that line the peritoneal cavity. Since the MOVCAR cells shed Muc16, this murine model may be important in understanding the immunomodulatory roles of this mucin. The shed Muc16 should also be found in the serum of mice bearing the 
MOVCAR tumors. The antibodies identified in the current study can therefore be used to monitor tumor progression in mice. These antibodies can also be used to purify Muc16 so that its biochemical and biological properties can be exhaustively studied.

\section{Conclusion}

In this study we demonstrate that Muc16 is expressed by murine ovarian tumor cells and can be detected by newly developed murine monoclonal antibodies that were initially generated against human MUC16.

\section{List of abbreviations}

EOC: epithelial ovarian cancer; ConA: Concanavalin A; $\alpha$ Me-Man: $\alpha$-methylmannopyranoside.

\section{Competing interests}

Anti-MUC16 antibodies used in this study were developed for commercialization by Neoclone Biotechnology. Dr. Zwick was employed at Neoclone Biotechnology when this study was conducted. The University of Wisconsin-Madison researchers have no competing interests to declare.

\section{Authors' contributions}

CARG conducted the RT-PCR and western blot ananlysis and was assisted in these experiments by JAB and JAAG. $\mathrm{MM}$ and CR helped in designing appropriate Muc16 primers. JC assisted in obtaining and maintaining murine ovarian tumor cells. MK assisted in standardizing the RTPCR protocols. RK, WT, and MZ were involved in the development of the anti-MUC16 antibodies. MSP designed this study and developed the manuscript.

\section{Acknowledgements}

We thank Drs. Denise Connolly and Beatrice Yin for providing us the appropriate reagents. Funding for this research was provided by grants from the Department of Defense (\#W8IXWH-04-I-0102), Ovarian Cancer Research Fund (UW/UWM.05), a charitable donation from Jean McKenzie, and start-up funds from the Department of Obstetrics and Gynecology to MSP. We are deeply grateful to Kathy Schell for her advice and help and acknowledge the support provided by the University of Wisconsin Comprehensive Cancer Centers Flow Cytometry facility, which is supported by a core grant (CA I 4520) from the National Institutes of Health. Funding for the development of the anti-MUCI6 antibodies was provided by NCI Contract NOI-CN-433I 3 to NeoClone Biotechnology (R. Kravitz PI).

\section{References}

I. Jemal A, Seigel R, Ward E, Murray T, Xu J, Thun MJ: Cancer statistics 2007. CA Cancer J Clin 2007, 57:43-56.

2. Bast $R C$ Jr, et al.: A radioimmunoassay using a monoclonal antibody to monitor the course of epithelial ovarian cancer. N Engl J Med. 1983, 309( I 5):883-887.

3. O'Brien TJ, Beard JB, Underwood LJ, Dennis RA, Santin AD, York L: The CA 125 gene: an extracellular superstructure dominated by repeat sequences. Tumour Biol 200I, 22:348-366.

4. Yin BW, Dnistrian A, Lloyd KO: Ovarian cancer antigen CAI 25 is encoded by the MUCI6 mucin gene. Int J Cancer 2002, 98:737-740.
5. Fendrick JL, Staley KA, Gee MK, McDougald SR, Quirk JG Jr, O'Brien TJ: Characterization of CA 125 synthesized by the human epithelial amnion WISH cell line. Tumour Biol 1993, I4:3 I0-318.

6. Gubbels JA, et al:: Mesothelin-MUCI6 binding is a high affinity, $\mathrm{N}$-glycan dependent interaction that facilitates peritoneal metastasis of ovarian tumors. Mol Cancer 2006, 5:50.

7. Patankar MS, et al:: Potent suppression of natural killer cell response mediated by the ovarian tumor marker CAI 25 . Gynecol Oncol 2005:704-713.

8. Connolly DC, et al.: Female mice chimeric for expression of the simian virus $40 \mathrm{TAg}$ under control of the MISIIR promoter develop epithelial ovarian cancer. Cancer Res 2003. 63:1389-1397.

9. Dinulescu DM, Ince TA, Quade BJ, Shafer SA, Crowley D, Jacks T: Role of K-ras and Pten in the development of mouse models of endometriosis and endometrioid ovarian cancer. Nat Med 2005, II:63-70.

10. Roby KF, et al.: Development of a syngeneic mouse model for events related to ovarian cancer. Carcinogenesis 2000, $21: 585-591$.

II. Mabuchi S, et al.: RAD00 I (Everolimus) delays tumor onset and progression in a transgenic mouse model of ovarian cancer. Cancer Res 2007, 67:2408-24I3.

12. Lloyd KO, Yin BW, Kudryashov V: Isolation and characterization of ovarian cancer antigen CA 125 using a new monoclonal antibody (VK-8): identification as a mucin-type molecule. Int J Cancer 1997, $71: 842-850$.

13. Largaespada DA, Jackson MW, Thompson NE, Kaehler DA, Byrd LG, Mushinski JF: The ABL-MYC retrovirus generates antigen-specific plasmacytomas by in vitro infection of activated B lymphocytes from spleen and other murine lymphoid organs. Immunol Methods 1996, 197:85-95.

14. Weissinger EM, Henderson DW, Mischak H, Goodnight J, Mushinski JF: Induction of plasmacytomas that secrete monoclonal anti-peptide antibodies by retroviral transformation. J Immunol Methods 1994, 168:123-130.

15. Kui Wong N, et al:: Characterization of the oligosaccharides associated with the human ovarian tumor marker CAI25. J Biol Chem 2003, 278:28619-28634.

16. Schulz BL, Packer NH, Karlsson NG: Small-scale analysis of $\mathbf{O -}$ linked oligosaccharides from glycoproteins and mucins separated by gel electrophoresis. Anal Chem 2002, 74:6088-6097.

Publish with Biomed Central and every scientist can read your work free of charge

"BioMed Central will be the most significant development for disseminating the results of biomedical research in our lifetime. "

Sir Paul Nurse, Cancer Research UK

Your research papers will be:

- available free of charge to the entire biomedical community

- peer reviewed and published immediately upon acceptance

- cited in PubMed and archived on PubMed Central

- yours - you keep the copyright

BioMedcentral 